\title{
Socio-technical systems for citizen empowerment: how to mediate between different expectations and levels of participation in the design of civic apps
}

\author{
Naomi Bueno de Mesquita*, Nazli Cila, \\ Maarten Groen and Wouter Meys \\ Digital Media and Creative Industry, \\ University of Applied Sciences Amsterdam, 1091 GC Amsterdam, \\ Netherlands \\ Email: naomi.buenodemesquita@student.kuleuven.be \\ Email: n.cila@hva.nl \\ Email: m.n.groen@hva.nl \\ Email: w.t.meys@hva.nl \\ ${ }^{*}$ Corresponding author
}

\begin{abstract}
In the context of the participation society, roles and expectations of citizens and municipalities are vastly changing. While designers explore the potentials of apps to empower citizens, municipalities are interested in data dashboards - accompanied by applications and platforms - to increase civic participation in public (space) issues. Due to diverse levels of data-literacy and expectations regarding the use of civic apps, more scrutiny is needed when it comes to claims of empowerment. This paper departs from the premise that designers often deal with disappointments in the balance of investment and participation span due to a lack of knowledge about underlying mechanisms. Relevant criteria are discussed through reflecting on two civic apps that were designed by the authors and analysing prominent existing civic apps that have citizen empowerment as their objective. By laying these out in a taxonomy the paper aims to examine why and where discrepancies occur in expectations and levels of participation.
\end{abstract}

Keywords: participatory tools; data submission; civic apps; design; citizen empowerment; local knowledge; public space.

Reference to this paper should be made as follows: Bueno de Mesquita, N., Cila, N., Groen, M. and Meys, W. (xxxx) 'Socio-technical systems for citizen empowerment: how to mediate between different expectations and levels of participation in the design of civic apps', Int. J. Electronic Governance, Vol. x, No. $\mathrm{x}, \mathrm{pp} \cdot \mathrm{xxx}-\mathrm{xxx}$.

Biographical notes: Naomi Bueno de Mesquita is a $\mathrm{PhD}$ candidate at $\mathrm{KU}$ Leuven (BE) with the subject Performative Mapping. The research is concerned with the potentials of digital mapping as a participatory research methodology for designers. Through self-designed map apps, she examines the affordances and limitations of digital mapping interfaces to foreground participation in public space or public issues. She holds a Bachelor with Honors in the field of Architecture from Gerrit Rietveld Academy, Amsterdam (NL) and a Master in Design, Art and Public Space from Elisava, Barcelona (SP). From 2014 until 2017, she was a Marie-Curie Research Fellow for the TRADERS project at Design Academy Eindhoven (NL). 
Nazli Cila is a Post-Doctoral Researcher at Digital Life Centre of Amsterdam University of Applied Sciences. She studied industrial design and obtained her PhD from the Delft University of Technology working on the topic of how designers can create effective and aesthetic metaphors to communicate through the products. Her current research combines data-driven design and design anthropology, in which she aims to better understand people and offer design solutions for their wellbeing through the use of sensor data, participatory sensing, and citizen science.

Maarten Groen works as a Researcher within the citizen data lab. In this lab Â, he is doing research on how citizens can gather data via their smartphone. He investigates how users themselves can create a valuable dataset by seeing the person as a sensor. His research also focuses on how the citizen's data can be coupled and compared with existing (open) datasets. He also has extensive experience in the processing, analysis and visualisation of these datasets. In the previous years, he worked for the research group Interactive Public Spaces (IPS) and Digital Life in which he worked on the CitySDK project (www.citysdk.eu). This project focused on sensor systems and dynamic (open) data in Amsterdam.

Wouter Meys works as a Researcher at the Citizen Data lab at the University of Applied Research in Amsterdam. He has a background in Electrical Engineering and Information Science. In the past, he worked on projects that focused on open data, intelligent sensory systems and public screens. Currently, he is doing research on several projects on participatory mapping and contextaware public displays. He has a strong interest in novel information services and citizen empowerment.

This paper is a revised and expanded version of a paper entitled 'Measuring Amsterdam' presented at Hybrid City Conference, Athens, 18 September, 2015.

\section{Introduction}

On January 2011, US President Obama issued a memo declaring transparency, collaboration and participation as his core values and he asked agencies to pursue those values with the use of innovative tools, methods and systems (Nath, 2011). Two years later, the Dutch King delivered a message from the government to the Dutch people saying that the welfare state was going to make a place for a participation society. In the UK, in that period, a transformation was underway from 'the big government' to 'the big society'. The proposals of these global developments assume that governments alone cannot solve complex social problems. Instead, by making the public services more accountable to citizens, decentralising power and expanding the opportunities for civic participation, it is aimed that an active citizenry will play a quantitatively and qualitatively greater role in tackling problems that affect communities (Hilton et al., 2010). Consequently, the roles/responsibilities of citizens and the roles/responsibilities of municipalities in society are vastly changing. For example, where in the past, a municipality was responsible for picking up trash, citizens might now become accountable for cleaning up their own neighbourhood. People have become an active 'maker and shaper' of the realities that affect their lives, rather than mere users of policies 
(Cornwall and Gaventa, 2001). It is argued that participation in these matters has an enormous potential to empower citizens (Pimbert and Wakeford, 2001).

Empowerment in its most general sense happens when people, individually or collectively, take action for pursuing better lives for themselves (Dom, 2012). It implies control and awareness; an empowered person exhibits a sense of control and efficacy over personal, social, and economic matters, and a critical understanding of his/her environment (Israel et al., 1994). At the community level, empowerment entails being enabled to engage on sociopolitical level in public (space) issues. By gaining awareness and control over the matters of concern, citizens become active players in the participation society. Community empowerment encompasses all the approaches that develop physical interventions to create a social change regarding those matters (Zimmerman, 2000). In this paper, we focus on one example of such category of interventions, namely civic apps, and compare the approaches of different civic apps that intend to empower citizens by engaging them with public (space) issues.

Civic apps often intend to make a physical intervention in order to make a change. Their value lies in voicing and mapping citizens' aspirations, which helps make relevant issues visible and addressable to other stakeholders such as civil servants. Most of these apps are focused on efficiency-based improvement of public spaces by enabling citizens to report on problems, such as having trash picked up or street lamps fixed. Google Play Store aptly entitles such apps as 'see-click-fix' (SeeClickFix, n.d.). We, however, consider that the real 'power' in empowerment comes from including local (and sometimes marginalised) people in the debate of what is to be considered a matter of concern and in this quest we see potentials in the use of civic apps. In our research and the projects that we have analysed in the scope of this paper, we, therefore, examine civic apps from this perspective. Although we acknowledge the value of see-click-fix apps in their potential to have one gain control and awareness over one's surrounding, we believe that they are less relevant in contributing to the more profound change in giving a voice to local groups and gaining access to local knowledge. While the term 'local knowledge' originally refers to indigenous or 'traditional' ways of knowing we would like to broaden the definition to encompass "tacit knowledge as embodied in life experiences and reproduced in everyday behaviour and speech" with an emphasis on including knowledge by any individual (Cruikshank, 2014, p.9). Not all forms of local knowledge, however, are compatible with existing systems, nor are they all recognised as valid and useful. Whose knowledge and which knowledge gets used are therefore inherently political questions.

The aim of this paper is to explore the potentials of civic apps as a means to produce local knowledge and give guidelines to designers and design researchers to create apps that afford to produce such knowledge and to address possible pitfalls in current app designs or in the design of new apps. In our exploration, we found that projects that strive to produce local knowledge have a tendency to fail in terms of active usage of an app or long-term engagement. In the design phase, this failure is partly due to a poor understanding of the context in which these projects operate. We believe that it is helpful to look at this context more in-depth and learn from previous experiments. Understanding discrepancies in expectations and participation might lead to better research questions and promote reflection on the benefits of civic apps.

In the remainder of this paper, we will first elaborate on these two discrepancies with regard to the design and use of applications and community platforms intended for citizen empowerment. For each discrepancy, we will present a case study based on our previous 
work and discuss the obstacles we encountered and the lessons we have learned. In the second part of the paper, we will present an overview of the kinds of commercial web and mobile apps that are designed with the aim to empower citizens in public space issues. We will analyse these apps on the basis of nine criteria found relevant for explaining the discrepancies in expectations and levels of participation, and arrange them in a taxonomy according to the design decisions taken. Lastly, we will discuss these criteria and decisions in the light of resolving the expectation and participation discrepancies and offer insights for designing and using civic apps in a more informed manner.

\section{Discrepancies in participation}

As stated earlier, the proclaimed welfare state is slowly but surely evolving into a participation society in which people are asked to take responsibility for their own lives and immediate surroundings. Citizen participation democratises decision-making with specific, tangible objectives and enhances knowledge, capacity, skills, expertise and social goals (Todman, cited in Doyle, 2008). Governments and municipalities are exploring new ways to have citizens more engaged with grassroots participation in policy-making and government, as demonstrated through the variety of worldwide contests intended for civic app development from open government data (Lee et al., 2016). However, even the most transformational intentions for citizen empowerment can meet a dead end when intended beneficiaries choose not to take part (Cornwall, 2008). When investigating the factors that influence user participation in apps and community platforms, there are many variables to take into consideration. The popularity of an app might, for instance, come down to depend on the marketing strategy of a project rather than the affordances of the app. Furthermore, we consider that the intrinsic motivations of citizens play an important role here. With regard to an operationally similar domain, online communities, Holohan and Garg (2005) found out that the main reasons for people to participate in distributed computing online communities are to be able to contribute to a worthy cause. Similarly, in their evaluation of the motivations for participating in citizen science projects - Galaxy Zoo project in particular - Raddick et al. (2013) listed the two major causes to be the interest on the topic of concern and the ability to contribute to a higher cause. Yet, when it comes to civic apps that rely on engaging and empowering communities we consider that this 'worthy cause' is often difficult to recognise. In many cases, the transparency on what kind of benefits a particular app would bring or where the data that is collected through the app ends up remains unclear for citizens. Lee et al. (2016) compared the success and impact of the civic apps created in a 10 years span, and indicate that the failure of many early open data initiatives and civic apps stemmed from the lack of civic benefit for the public and the government. The successful apps that are being downloaded and frequently used by citizens work closely with the cities to formulate relevant issues with an emphasis on what utility the app could provide and what the expected outcome and benefit of the app could be for the citizens and the government involved.

In addition to a perceived benefit, we consider that privacy concerns also play a crucial role in participation when it comes to using location-based applications. In our own pilot studies, we also observed that people were generally not inclined to participate. The cautious attitude in submitting data can be explained by a higher awareness 
regarding the use of other location-based apps where there is little or no consideration for privacy issues. Participants who do not want to participate often refer to services that are provided by companies who have made a business model out of the use of citizen data. Our observation is that many of these participants are not well informed about how data is collected/distributed/used in different applications or in the way they make use of services or applications in their everyday lives, thus confirming a lack of data literacy. As a consequence, it is increasingly more difficult for designers and design researchers who work with ICT to set up projects driven by a goal for citizen empowerment to be perceived as credible when asking people to submit data with their own phone. This 'problem' continuously presents itself in projects that deal with data submission. Below, we will give an example of a project that involved the use of a self-designed locationbased app where a clear resistance was encountered.

\subsection{Case study: what moves you? a collective real-time mapping of Eindhoven's Dutch design week}

During Dutch Design Week (DDW) 2015, people were invited to participate in the cartographic exploration 'What Moves You?': A collective real-time mapping of the city's transformation during Eindhoven's DDW. DDW's visitors collectively became the creators of a map that showed the feelings that circulate during DDW. The results of this research were presented daily in the public spaces of Eindhoven between the different participating venues and one evening at MU art centre for the design talkshow Create Out Loud. People that visited the city's event were invited to collaborate in the cartographic exploration while visiting the different venues. They were asked to use the web app 'What Moves You?' (2015) on their mobile phone and designate a feeling to a DDW location, after taking a picture of the 'thing' (object, place, person, and so on) that triggered that feeling. The data was uploaded and became directly visible on a map that could be accessed by going to a website. The real-time map demonstrated the areas of Eindhoven (comparing the different venues of DDW) that were more or less emotionally laden, what emotions were felt where, and how these feelings evolved in time. It furthermore could tell us something of the collective experience of the city and its different venues. For example, many pictures of the same object would tell us that the work in question triggers an emotion that is felt collectively, but in case a work or venue has many different emotions linked to it, it tells us that people experience different things with the same work or venue. The pictures demonstrated 'the thing' that collectively triggers a certain emotion (Figure 1). The installation at MU art centre (one of the participating venues), for example, was experienced very diversely by the visitors. The pictures and subscriptions reveal that the installation was experienced as exciting, moving, confusing and boring. It might be due to the fact that the program for the space was changing throughout the day and the installation was only 'in use' during the evenings. Additionally, a heat map demonstrated the kind of emotions that were felt in certain areas or venues in the city. The heat map (Figure 2) depicts the places in Eindhoven that were more or less emotionally laden during this event, from blue (emotions that start to be mapped) to red (very emotionally laden places). The three main areas where the event took place - Strijp S, the city centre and Sectie C - are clearly highlighted. Figure 3 is a zoom of Strijp S (one of the participating venues of DDW). By scrolling over the map, the emotions appear of the selected area. The bigger the words are represented, the more often the emotion was selected by the visitors. In this case 'excited' 
was the most often chosen emotion for this venue, followed by 'surprised' and 'curious". Zooming in allows showing more detail of the smaller emotions (in quantity) that are felt. By using the app 'What Moves You?', visitors became the authors of the DDW map with which they were able to contest the DDW maps created by the event's organisers or partners.

Figure 1 The installation at MU art centre. An example of pictures that were taken by the visitors with the app 'What Moves You?' to demonstrate what thing or venue triggers a certain emotion during DDW (see online version for colours)
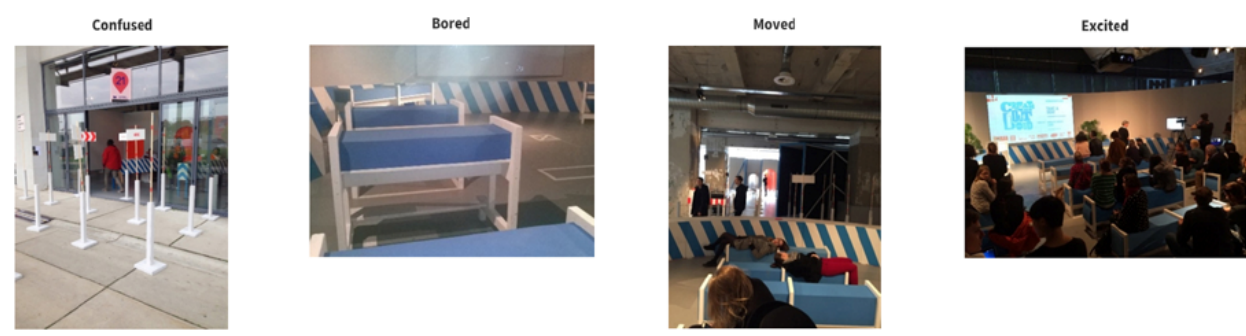

Figure 2 A screenshot of the real-time mapping 'What Moves You'. The heat map depicts the places in Eindhoven that were more or less emotionally laden during Dutch Design Week event in 2015, from blue (emotions that start to be mapped) to red (very emotionally laden places) (see online version for colours)

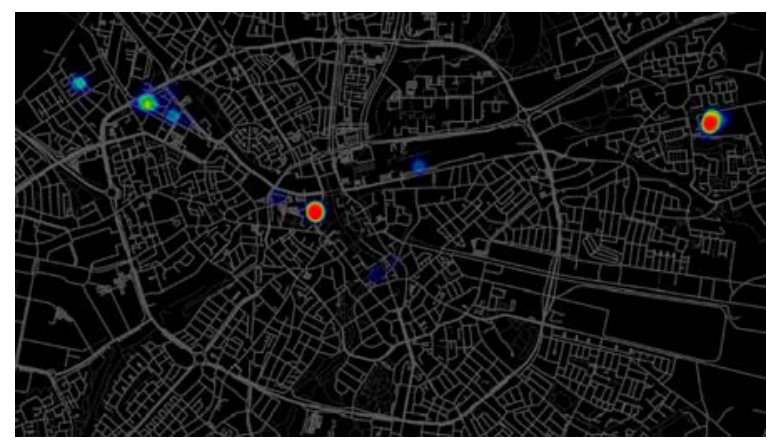

Figure 3 A zoom of Strijp S, one of the participating venues of DDW. Zooming in allows showing more detail of the smaller emotions that are felt (see online version for colours)

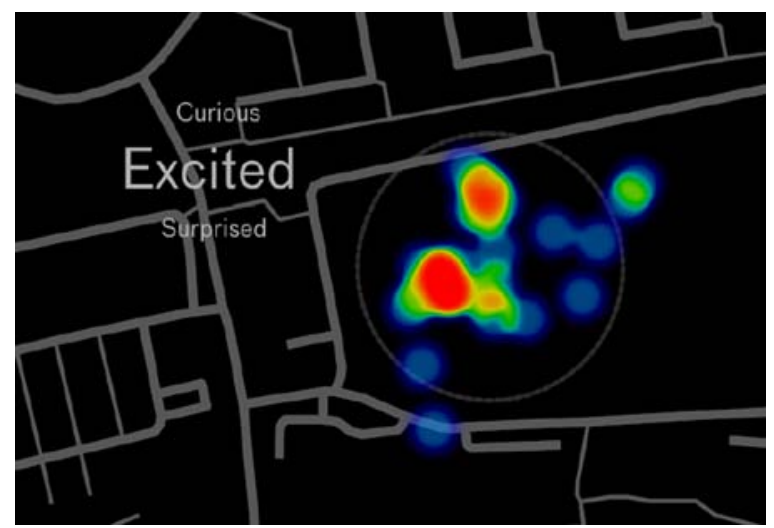


The designer of the project walked in Eindhoven between the different venues every day with a measuring wheel on which a projector was mounted (Figure 4), doubling as a presentation device in which live shows of the changing map were presented to the public (Figure 5). The idea was that the growing map would spark curiosity and seeing a direct result of one's actions would create incentives for participation. A total of 116 people participated in the mapping and almost all of the participants that the designer spoke to and that were willing to collaborate mentioned not to have a problem with submitting their data for public participation. The designer visited the different venues every day for an equal amount of time and divided the flyers and poster invitations equally among the different venues. Some people were very excited to participate but most rejected the invitation. Several designers who have their studio space at one of the participating venues were keen to find out how their works were perceived by visitors (Figure 6). At a leading design institute as participating venue in the event, however, people generally wanted to see the results of the map rather than participate in it. The designer became entwined in a number of fierce discussions (amongst other with a teacher of the institute) regarding the use of ICT in design. Some of the things that were mentioned: "I don't use internet outside of my house because I don't trust it.”, "I only use the internet at home. If I had it on my phone I would be on Facebook all day". "I have a very old phone”, "I don't want to use my own phone for this”. “The digital is not my thing”. The project turned into an ethnographic exploration to uncover aspects regarding user participation rather than creating a citizen-produced map. The project did not have enough diverse users to create maps that could be held against the ones that were created by the organisers of the event. It did, however, give insight in data-literacy among the public and clarified the diverse incentives for participation within this user group.

Figure 4 A growing map was projected in public space and in the participating buildings of the different venues. The maps and the (performance with the) measuring wheel were meant as a conversation piece and as a means to create incentives for participation. The measuring wheel was designed by Karianne Rygh and Rinze Borm (see online version for colours)

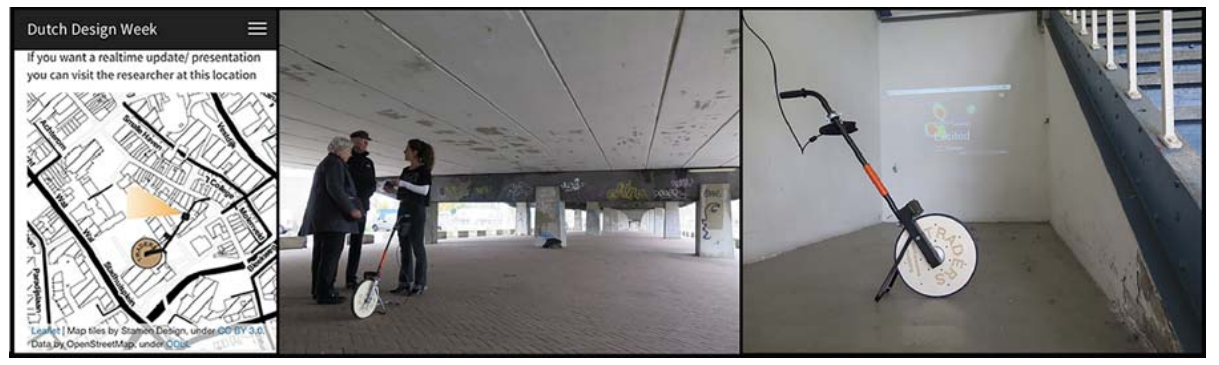

An evident discrepancy in data-literacy among citizens and between citizens and designers and design researchers is a relevant aspect to take into consideration when working with these type of ICT applications. As a result, in pilots often only certain kinds of people participate; e.g., people who have the time or who are interested in technologies. Furthermore, the role of the designer or design researcher easily transforms into one of an educator by providing citizens with data-literacy. This development might not be productive as the designs will continue to involve the participation of some actors over others, thus continuing to generate inequalities or turn designers into educators. Furthermore, a trend of participation fatigue seems to present itself when it comes to the 
use of ICT. Many people's reactions, when being asked to participate in the experiment in Eindhoven, clearly demonstrated this fatigue according to the designer's experience. Lowndes and Sullivan (2004) describe a 'consultation overload' that stems from various organisations or companies trying to enlist people in citizen participation activities (2004, p.69). To avoid this, we consider that design researchers and public servants need to think of ways that can maximise efficient use of resources while minimising participation fatigue. One way to achieve this is by offering some sort of dialogue and reciprocity to the citizens. Much depends on how people take up and make use of the data, which would help them nurture, voice and empower themselves and their community. The most frequently used mobile applications come from the government, municipalities or private organisations that allow citizens to get information, add value to it and give it back to the government, municipalities, or private organisations to solve important problems and create added value (Sandoval-Almazan et al., 2012). A good example of this is the Urban Forest Map (n.d.), which is a collaborative project between the city of San Francisco and Friends of the Urban Forest, a local NGO. The website allows citizens of San Francisco to view the trees of the city and add or update existing information on the map, which is then sent back to the municipality. Citizens are crowdsourcing a better understanding of their city’s urban forest with which environmental value is generated (Nath, 2011).

Figure 5 A presentation of the map was given to a designer in Sectie C (one of the participating venues) who has a studio space in this building. He wanted to know if his work was mapped and what emotions were subscribed to it by the visitors (see online version for colours)

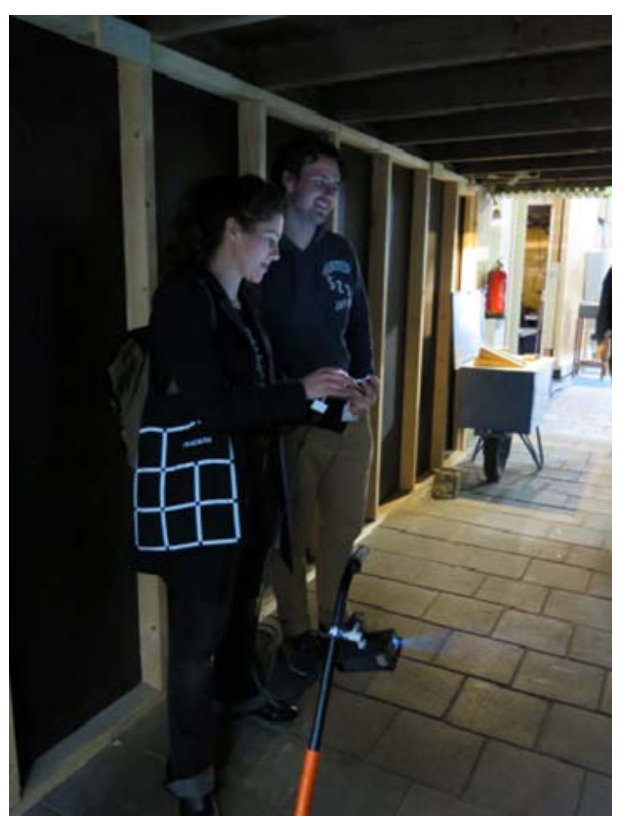

\section{Discrepancies in expectations}

Increasingly more aspects of our daily lives in the city can be measured using sensor technologies. The Air Quality Egg (n.d.) and Smart Citizen Kit (n.d.) are examples of 
tools that allow citizens to measure climate conditions and air pollution levels within their living environment (Diez and Posada, 2013). Although these sensor systems enable citizens to gather information about their surroundings by using quantitative measurements, societal issues within a neighbourhood are rather more challenging to measure, as they depend on citizen input. Communication technologies and locationbased applications can be powerful tools to support and promote participation and (sociopolitical) civic engagement (Brown and Kyttä, 2014). Applications such as Fix My Street (n.d.), for example, claim to contribute to community building by creating incentives for collective action regarding liveable environments (King and Brown, 2007). But how do these systems operate? Whose expectations are met with their use? In what way do they empower citizens? Without understanding who initiates a project and to what end, it is questionable what the value of data-collection, data-submission and data visualisation is (or better put: for whom they are of value) and it is not clear how different stakeholders can benefit from and act upon this data to instigate change. For example, civil servants have to make decisions that involve policies on different scales (such as decisions that touch political agendas of the municipality officials and political agendas of city councils) which makes it increasingly more difficult for them to know what data they can act upon. Understanding their position might lead to better-informed decisions on which kind of data can be useful to collect. Similarly, understanding citizens' motivations and daily use of technologies will help design tools that can be appropriated and further developed by its users. If designers want to avoid being involved in unethical considerations, such as the instrumental use of art or design for a political or corporate purpose, they should engage with this question prior to entering such a project.

Figure 6 A discussion about the map and use of the app at Design Academy Eindhoven (one of the participating venues) (see online version for colours)

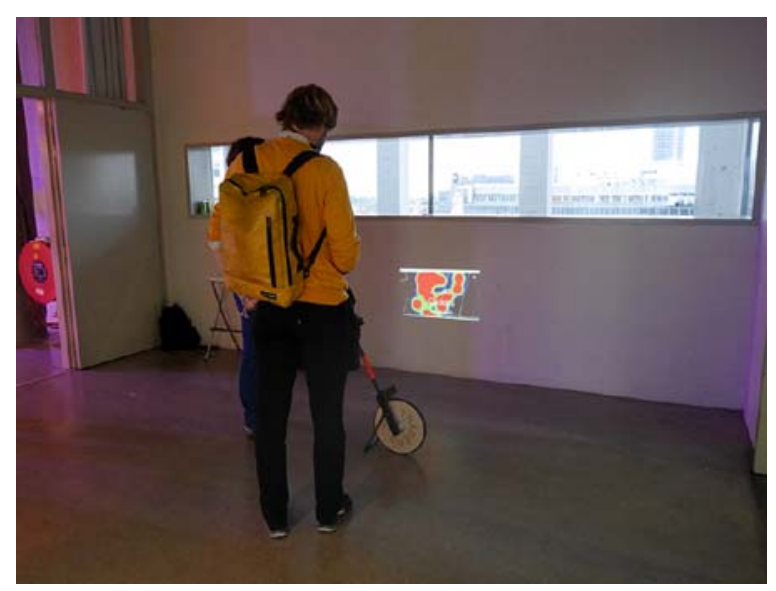

\subsection{Case study: measuring Amsterdam}

The Measuring Amsterdam project was set up with the idea to use people's observation rather than sensor systems as a way to collect data on neighbourhood scale (Measuring Amsterdam, 2014). The tool was tested on two occasions each involving an iteration of 
the tool. For both pilots, an event was organised in which citizens, municipality, students, researchers and professionals were invited to participate. Both events consisted of presentations about bottom-up initiatives in smart cities, after which the participants were invited to go outside to test the tool in small groups. At the end of the fieldwork, the results were immediately presented and a discussion took place.

The first pilot took place at the Amsterdam University of Applied Sciences in June 2014. An application was designed which participants of the event could use to gather information about encounters on the street. The web app worked on any smartphone or tablet with a modern browser. In the pilot, the functionality of the app and the technical implementation of the platform were tested. The area of investigation was a busy street in Amsterdam called the Knowledge Mile (n.d.). The Amsterdam University of Applied Sciences is located along this street and uses it as a Living Lab for experimentation. A Living Lab is an open innovation ecosystem, allowing research to be performed in a real world setting (Almirall and Wareham, 2011). The neighbourhood where the street is situated is characterised as a residential area amongst which many companies and universities are located.

Prior to this workshop posters were hung and flyers were spread around in the university and the researchers' networks. A total of thirty people responded; mostly professionals, researchers from the University of Amsterdam and people from the municipality. The pilot was set-up as follows: the participants were asked to form small groups of 2-3 people. The twelve groups were assigned a specific area of the Knowledge Mile. In each group's area of investigation, the participants were asked to make annotations of a list of predefined categories by using a mobile web app. The categories had been created by four researchers of the Amsterdam University of Applied Sciences and were based on previously reported problems in this street, such as dangerous traffic situations due to people who use their mobile phones while cycling. In the web app, a form was generated from the collaboratively defined variables. As shown in Figure 7, measurements could be entered by participants by selecting a main category from the dropdown menu. Depending on the selected category a new dropdown menu was shown to enter more specific values. To illustrate, if a user would want to enter data about mobile device usage, a dropdown menu would appear asking which type of mobile device was being used (i.e., smartphone, laptop, etc.). Another question would then be asked about what that person was doing at that moment (i.e., walking, sitting, cycling or driving). 1050 measurements were performed in the $1 \mathrm{~h}$ period. By using the GPS location of the device or by dragging a marker on a map, the location was linked to the observation. The data was stored in a NoSQL database and was made available in the open standard format GeoJSON. Because the categories were predefined, it was possible to design the infographics beforehand and fill in the collected data directly after finishing the pilot. Within an hour after the fieldwork, we were able to demonstrate all the geotagged data in the form of maps and infographics. These visualisations (Figure 8) were presented to the participants and functioned as conversation piece after the fieldwork. The designers received very positive feedback from the participants about the ability to see the maps and infographics directly after the fieldwork. They mentioned that they felt a sense of ownership with the maps and with the ability to see the submitted data of all the participants in real-time. 
Figure 7 Screenshot of the web app Measuring Amsterdam (see online version for colours)

\section{(2)}

\section{With this form you can input your City Health data}

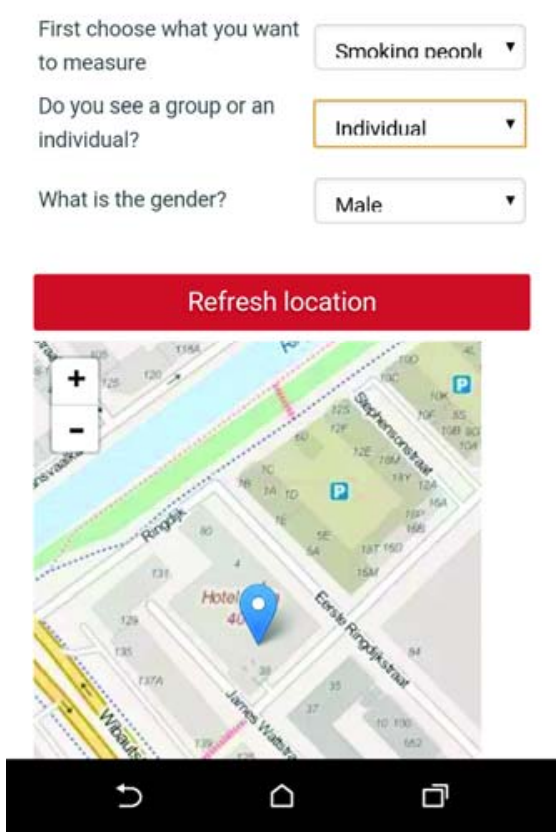

Figure 8 Example of a visualisation that was created right after the fieldwork. The infographic demonstrates what types of activity people are involved in while using a mobile device (see online version for colours)

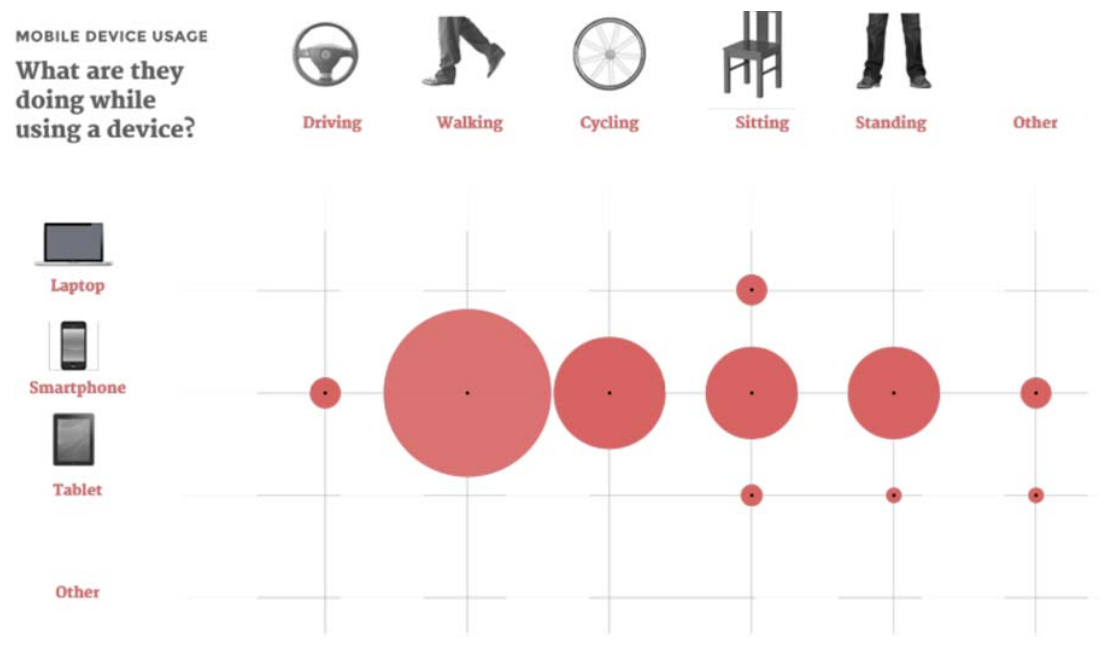

In the first pilot some participants mentioned they wanted to add their own categories because they were sent to areas where not many things could be observed in relation to the predefined categories. The participants also mentioned that they felt the need to add 
more context around a datapoint in the form of a free text-field. Based on these findings, an iteration of the tool was made and a second event was organised. This time the tool would enable the participants to choose own categories and add more context to a datapoint. This second pilot was held in October 2015. Among the 28 participants were students, researchers, professionals, municipality officials and local residents. The setup was the same: the pilot started with small presentations, after which an hour was reserved to use the tool in small groups, finalised with maps and infographics of the generated data that was accompanied by a discussion. The area of investigation also remained unchanged. Participants in this pilot were asked to make an annotation of things that they thought could be improved and to present a possible solution for their reported problem (Figure 9). This time the participants were free to choose what categories to map by making a picture of the problem that they wanted to report on (Figure 10). The participants were furthermore able to see the input from the other participants in a gallery. This function was built in with the idea to inspire other participants and to share opinions (when clicking on the input from one of the other participants there was an option to like or dislike the contribution). In the $1 \mathrm{~h}$ period, a total of 55 problems and solutions were reported. The application used the GPS location of the phone while the data was stored in a NoSQL database and published in a GeoJSON format under the open data licence. The data from the pilot was visualised on a dashboard (Figure 11) which demonstrated all of the pictures regarding reported problems or issues in the neighbourhood that the participants added together with a presented solution.

Figure 9 A screenshots of the mobile application used in the second pilot of Measuring Amsterdam. Participants were able to describe problems and solution and add a picture (see online version for colours)

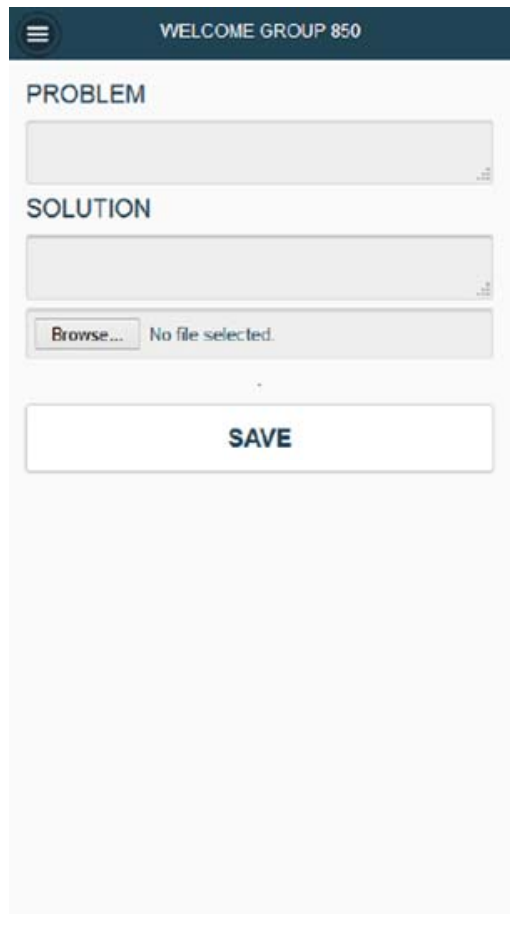


Figure 10 A screenshot of the application demonstrating how users were also able to see the contributions of all the other participants (see online version for colours)

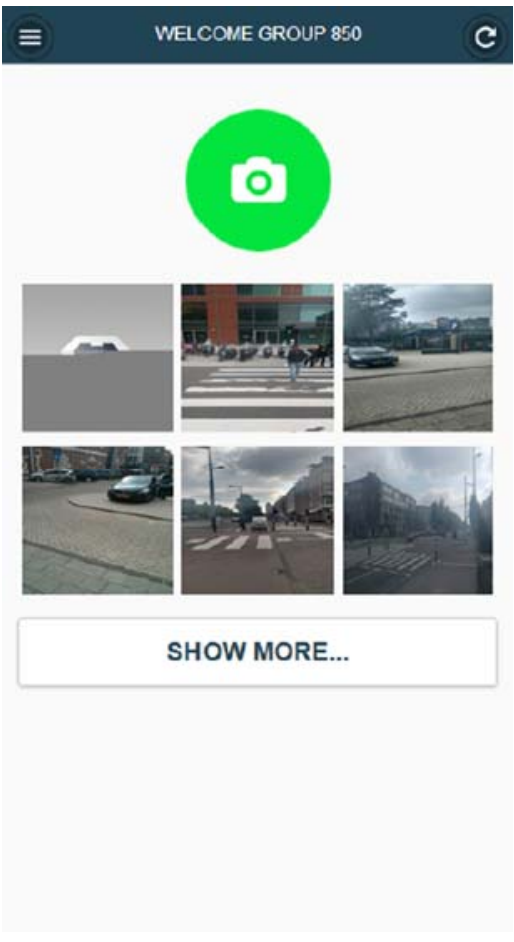

The Measuring Amsterdam tool offers open data via a publicly accessible API. The data that is collected when using the Measuring Amsterdam tool could be of interest to the municipality as it provides insight into things that are perceived as problems and potentials by citizens on a neighbourhood scale. Striving to understand how the next iteration of this tool could be useful for the municipality of Amsterdam, the series of interviews were held with two municipality officials and an expert in the field, who is a research associate at the Citizen Data Lab of the Amsterdam University of Applied Sciences and actively involved in the procedures of the municipality of Amsterdam. The interviews helped the designers gain knowledge about wishes and expectations of the municipality regarding the use of such tools. As it is important to understand in more detail what the different roles of the municipality entail, we will first describe how the municipality of Amsterdam operates, after which we will come back to their response regarding their expectations from the use of such participatory tools.

As mentioned by the expert in our follow-up interviews, the municipality of Amsterdam consists of civil servants, management boards and politicians. Firstly, there is a central organisation which oversees the entire city of Amsterdam. This organisation consists of different departments that have expressed an interest in working with civic apps, such as; the CTO office (a department that is responsible for the acceleration, advising and facilitating of new technologies within the city), the OI\&S department (working on the topics of Research, Information and Statistics), the ICT department itself (more than anything, this department is burdened with the administrative tasks of the municipality), and the department of Public Services (this department is the contact point 
of the municipality towards its citizens and business owners when it comes to central services). Secondly, the municipality of Amsterdam operates on a more local level with seven districts divided into 22 neighbourhoods. These districts make so-called area development plans on a yearly base (De Gebiedscyclus, 2016). The plans describe the key issues on which the areas will be working on. When looking at how the municipality and its different departments make new plans to improve the neighbourhood, we can identify three phases: analysis, agenda and plan. First, the department of OI\&S makes an analysis on a certain topic, which together with the expertise and input of local civil servants results in an agenda that leads to the creation of a new plan or policy change. There is, generally speaking, little knowledge about ICT across the board of the municipality. Decisions or policies regarding the use of ICT and development of participatory tools such as civic apps are not made by one specific organ or in a structured way but rather ad-hoc.

Figure 11 Website showing an overview of the submitted data during the second pilot of Measuring Amsterdam. It was used as a conversation started after the pilot. See also: http://www.measuringamsterdam.nl/event (see online version for colours)

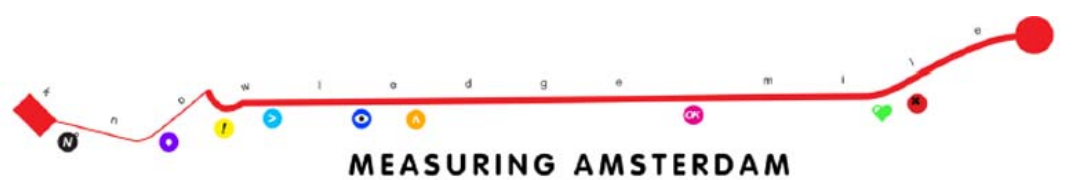

ans aseact
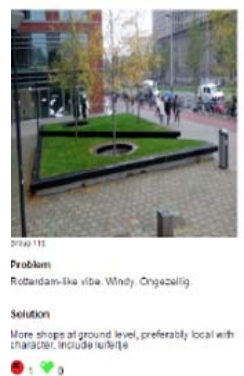

?.

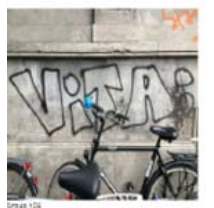

Probiem

solition
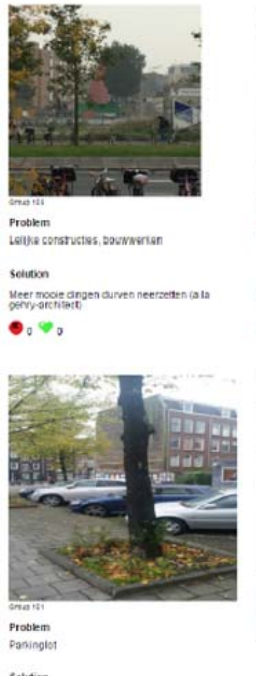

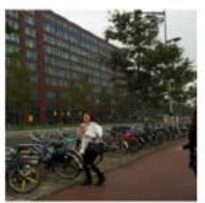

Prosem
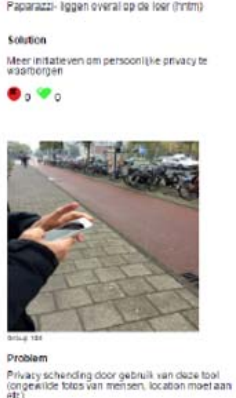

Sadican
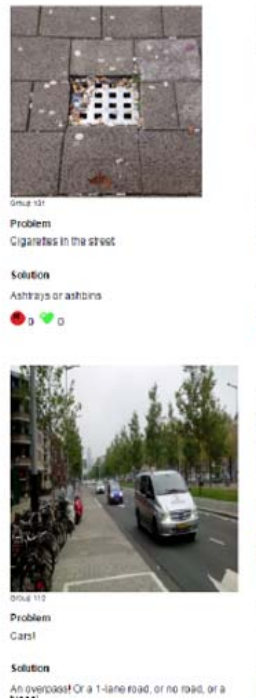
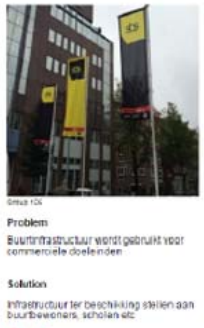

- $0 \%$

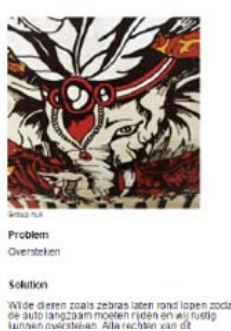

When it comes to OI\&S's and CTO's interest in participatory tools, the following wishes and expectations were expressed:

- $\quad$ Civic apps should help make an end to bureaucratic fuss. The idea is that processes in which civil servants were needed in the past (such as getting a parking permit) can now be arranged by citizens themselves through the use of ICT. 
- Civic apps should empower individuals and communities through data dashboards (using open data and social media analysis). The idea is that through these dashboards citizens can find out what is happening in their neighbourhood, take ownership and become more actively engaged with local issues and within a community. It is argued that if you expect from citizens to become active agents you have to provide them with the right tools, knowledge and information.

- A social network platform should be incorporated in these dashboards that make it possible to convert them into co-produced content instead of having citizens as passive subjects who only receive information. In other words, information is not only made transparent and offered to citizens, but citizens are also expected to become active in collecting data and responsible for the use of the dashboard and the further development of it (R. Priester, personal communication, 15 January 2016).

The municipality of Amsterdam employs approximately 13.000 civil servants. The scale makes it very hard for people to know who to contact if they want to initiate a grassroots initiative, such as a civic app. Neighbourhood teams have been set up recently for this reason, with the aim to create a contact point with the municipality. From the perspective of the CTO office, the main expectation of a tool such as Measuring Amsterdam is that it should help them get an overview of current 'hot topics' on a neighbourhood scale. For the CTO office, it is crucial that citizens expectations are managed correctly when using tools that are created by third parties (such as companies or researchers). It is argued that citizens have to be informed about who initiated a project and what the role of the municipality is within it to avoid a scenario in which citizens do not get direct feedback and hold the municipality responsible for it. When asking the CTO office what they foresee as possible obstacles in using such tools, they mentioned that they depend on the drive and commitment of citizens themselves to make real changes. They also have specific interests in using civic apps when working on new area development plans. Such tools could help inform the municipality about noteworthy issues, focus points, and upcoming changes in a neighbourhood. They foresee that citizens will have much more influence on these area development plans in the future and that through participatory tools relevant issues in a neighbourhood can easily be detected by the municipality. The data from such tools can, furthermore, be used as a conversation starter in local neighbourhood meetings.

If we look at the pilots and the issues reported with the Measuring Amsterdam tool we observed that people felt the need to report on or introduce more complex personal issues, such as the lack of public parks rather than a fallen tree. For the municipality, it is currently difficult to handle such reports. They require more time and planning, as well as have more impact on other citizens compared to the see-click-fix reports. In an interview that was held with the Amsterdam-East municipality neighbourhood team, we found that the problems regarding fixing things on street level (such as broken pavement or broken lampposts) are easily taken on by the municipality because they can implement these reports within their own systems. Many 'problem reporting' applications and platforms have popped up after the increased adoption of open standards such as the Open311 standard (Patel, 2015). The Open311 standard is an API-platform which makes it easier for apps to provide the above-mentioned service as they can easily connect to the service of different municipalities whom all accept the Open311 data format. The municipality can pre-define certain service codes which are accepted and applications can use these service codes to make the communication with the municipality as simple as possible. As 
the municipality knows what type of data to expect, these kinds of reports can easily be forwarded to the corresponding department within the municipality. The more complex issues, however, require the involvement of possibly many different departments. When handling such complex issues it is important to keep citizens in the loop, in order to build trust in that their input is being used. Citizens must be informed about what happens with their data and what they can expect the municipality to do and when. If these expectations are not met citizens might not feel heard, even if this is not necessarily the case. More open-ended questions or issues that do not have a service code definition are therefore more challenging to deal with for the municipality. We see potentials for uses of such tools in which citizens are able to share very specific local knowledge or community wishes. The municipality could use this information to have more tailored solutions on a neighbourhood scale, for example by implementing it in the agenda of a new area development plan. The challenge for the designer is to take into consideration how the data formats of a civic app can best connect to existing municipal systems while respecting citizens' wishes and expectations when it comes to use and data-submission.

\section{Analysing civic apps}

So far in this paper, we focused on portraying the discrepancies that we observed and experienced in the design and use of self-designed mobile/web apps that aim for citizen engagement in public space issues. In order to give a better sense of the kinds of applications that are being made available for current web and mobile platforms and reflect on their benefit for citizen participation or citizen empowerment, we introduce in this section several commercial examples and analyse them according to various criteria that were chosen. We consider that the result of this analysis might lead to betterinformed choices for the design of such tools. Similarly, understanding citizens' motivations and daily use of technologies will help design apps that can be appropriated adequately by its users.

We selected projects which aim to engage citizens with a common public issue (see Table 1). Our criteria for selecting these projects were that the data was collected by citizens and we had information about the different stakeholders involved. All selected projects have a different mix of functionalities and/or type of initiator. There are many more see-click-fix apps to be found (most of them are very similar to the ones we have selected), but these have been left out of this table to make the overview more diverse.

We compare and contrasted each app listed in Table 1 through a visual taxonomy that can be seen in Figure 12. The thickness and colour of the lines that are connecting the apps in the figure are distinguished according to two main criteria: how much the app has been used to collect data (until the moment of writing of this paper) and how empowering its use is. These two criteria were considered to be directly relevant for the previously introduced discrepancies in the paper on participation and expectations. As we did not have information on the user base of the apps, we based the thickness of the line on the quantity of recently added data by users relative to the size of the apps target group. The second criteria, the level of empowerment, was evaluated based on the definition we made earlier in the paper for the app to produce local knowledge and eventually tailor a policy to a local context. The more the app has the potential to do this, the darker the colour is depicted in the figure. 
Table 1 The civic apps used in the taxonomy

\begin{tabular}{|c|c|}
\hline App & Description \\
\hline Verbeterdebuurt & $\begin{array}{l}\text { A commercial platform that serves as the connection between the citizen } \\
\text { and the government. Users can add a photo, select a location and problem } \\
\text { category, and add a description. Besides reporting problems, they also } \\
\text { allow users to submit ideas about improvement of a certain location, but as } \\
\text { stated on their website this is not sent to the municipality. Furthermore the } \\
\text { platform also contains a map overview of all added data points categorised } \\
\text { by open submitted problems, fixed problems and ideas. Users are able to } \\
\text { comment on added reports and ideas (www.verbeterdebuurt.nl) }\end{array}$ \\
\hline BuitenBeter & $\begin{array}{l}\text { A commercial multi-platform mobile application that serves as a } \\
\text { connection between the citizen and the government for reporting issues in } \\
\text { the public space. Users can add a photo, their location, a predefined } \\
\text { category and a description. There is no overview of reports that have been } \\
\text { submitted by others. It is unclear, for this reason, how many reports are } \\
\text { actually fixed (www.buitenbeter.nl) }\end{array}$ \\
\hline $\begin{array}{l}\text { Commonwealth } \\
\text { Connect }\end{array}$ & $\begin{array}{l}\text { A commercial multi-platform mobile application that serves as the } \\
\text { connection between the citizen and the government. Users can add a photo, } \\
\text { select a location and problem category, and add a description. In the app, } \\
\text { nearby reports can be viewed on a map. It is also possible to leave a } \\
\text { (location-based) message to the community in the app, which will also } \\
\text { show on the map. Other users can reply and/or like a report or message. } \\
\text { The top reported categories mentioned on the website are: pothole, trash } \\
\text { and, graffiti. According to the website, the average response time is } 2.8 \\
\text { days to acknowledge an issue and most issues were closed or solved within } \\
16 \text { days in } 2015 \text { (commonwealthconnect.io) }\end{array}$ \\
\hline CleanUp! & $\begin{array}{l}\text { An iOS reporting tool from the municipality of Amsterdam. Users can } \\
\text { report issues in the public space and also attach a picture. Users can choose } \\
\text { to let the municipality keep them updated on the progress of fixing the } \\
\text { problem. There is no overview of other reports. Because of this, it is } \\
\text { unclear how many reports are actually fixed } \\
\text { (itunes.apple.com/nl/app/clean-up!/id } 449847909 \text { ? }=\text { en\&mt = 8) }\end{array}$ \\
\hline FixMyStreet & $\begin{array}{l}\text { A (non-profit) platform that serves as the connection between the citizen } \\
\text { and the government. FixMyStreet makes sure the report arrives at the right } \\
\text { location inside the government. This could be via just an email or via the } \\
\text { Open311 standard. Users can select reports from a predefined set of } \\
\text { categories. Looking at the reports statistics, } 500 \text { UK councils are receiving } \\
\text { reports. Around } 16,000 \text { issues are reported per month } \\
\text { (www.fixmystreet.com) }\end{array}$ \\
\hline Hallo IJburg & $\begin{array}{l}\text { A community platform created by the community. It is multi-purpose: from } \\
\text { sharing events to presenting projects in the area and giving news from the } \\
\text { neighbourhood. For this research we specifically look into the 'wishes' } \\
\text { section. Here citizens can add their wish to improve or change something in } \\
\text { the neighbourhood. Wishes are categorized in seven categories. Other users } \\
\text { can respond to ideas. Users can also choose to like the wish, actively help } \\
\text { with the wish, or become one of the main initiators of the wish. A total of } \\
225 \text { wishes have been submitted, but looking at the date of added wishes, } \\
\text { the amount of responses has dramatically decreased after the first year. } \\
\text { Only } 10 \text { ideas were submitted in 2015, while in 2014, } 215 \text { ideas were } \\
\text { submitted (halloijburg.nl) }\end{array}$ \\
\hline
\end{tabular}


Table 1 The civic apps used in the taxonomy (continued)

\begin{tabular}{|c|c|}
\hline App & Description \\
\hline Betaville & $\begin{array}{l}\text { A tool created by design researchers which allows people to use software to } \\
\text { create 3D models of buildings, a district, or an entire city. The tool can be } \\
\text { downloaded and used as a desktop application. Created models can be } \\
\text { shared and edited by others. While it is mentioned that the tool should be } \\
\text { usable by anyone from individuals to design firms and the municipality, the } \\
\text { tool is quite complex. } 50 \text { models have been added so far by } 16 \text { users in } 2 \\
\text { years. The largest contributor has added } 20 \text { of the } 50 \text { models (betaville.net) }\end{array}$ \\
\hline $\begin{array}{l}\text { Idee voor } \\
\text { je Buurt }\end{array}$ & $\begin{array}{l}\text { A community platform initiated by the municipality. Citizens are able to } \\
\text { submit ideas in free format to the website. They can be linked to either a } \\
\text { specific neighbourhood or to the city in general. Other users can support a } \\
\text { submitted idea. } 30 \text { ideas have been submitted in 2015, but there are almost } \\
\text { no responses on the submitted ideas from the municipality or other citizens } \\
\text { (oud.amsterdamsmartcity.com/projects/detail/id/95/slug/change-by-us-in- } \\
\text { amsterdam?lang = nl) }\end{array}$ \\
\hline Kerrokantasi & $\begin{array}{l}\text { A municipality initiated website which allows citizens to voice their } \\
\text { opinion about development plans in the city. In some cases users can only } \\
\text { comment on already created plans for a certain area. In some other cases, } \\
\text { users are also able to select the best option in their opinion from multiple } \\
\text { presented options of how an area could be developed. Users are encouraged } \\
\text { to also elaborate on why they think the option they chose is the best one } \\
\text { (kerrokantasi.hel.fi) }\end{array}$ \\
\hline
\end{tabular}

When comparing the apps in relation to the data they collect, their ownership, technical infrastructure and content, we also identified some criteria that give insight about the use of these applications and help explain the two discrepancies. These are:

- Who initiated the project or the design of the application, distinguishing between four stakeholders: design researchers (3 apps), NGO’s (2 apps), municipalities (3 apps) and companies (3 apps).

- $\quad$ The idea(l)s that were envisioned with the design of the application regarding engagement type: apps that enable citizens to report problems (5 apps) and apps that enable citizens to introduce solutions, ideas, or feelings for a better living environment in relation to places or issues (6 apps).

- If the data has a publicly accessible API. Data that is collected via the tool could be published under the open data licence and retrievable via an API (2 apps). This means that anyone can retrieve the data that is in the system and use it without any restrictions in their own projects or tools. Or there is no publicly accessible API (9 apps).

- How data is collected, distinguishing between location-based (7 apps) and nonlocation based apps (4 apps). The location-based ones refer to an application in which one's latitude and longitude position are automatically linked to the data that is submitted. The non-location based ones allow to add a location regarding the issue without necessarily being present on the location (e.g., behind a desktop at home).

- If data can be traced back to an individual. With regard to privacy issues, this is an important feature. Some apps require to register and can trace the user after registration, while other apps leave the user completely anonymous. In the 
taxonomy, we can see that only the apps that were set up by design researchers (3 apps) leave the user incognito.

- If the data is collected with predefined categories. In this case, we make a distinction between someone who has to choose between categories in a dropdown menu/predefined text options (7 apps) or if data can be submitted in a more 'open' format (4 apps) which contains free text descriptions, photos or drawings.

- Whether or not the municipality has the ability to directly act upon the data. This means that reports should directly arrive at the municipality in their preferred data format after reporting it via the tool (5 apps). The municipality can then (automatically) send it to the department that can best resolve the reported issue. Or the data does not end up at the municipality (6 apps).

- $\quad$ The scale for which a certain issue is reported, distinguishing between local (6 apps) and city scale (5 apps). For example, reporting trash is considered a city-wide issue, while expressing a specific feeling or wish with regard to a place is considered a local issue.

- $\quad$ The idea(l)s that were envisioned with the design of the application regarding period of usage. Some projects are clearly aimed at short-term usage (5 apps) (for instance during a specific event) while others are aimed at continuous usage (6 apps) and at different moments of the day or month.

In our search for apps and platforms, we found many examples of tools that aim to contribute in making the city more efficient or cleaner. The first five applications in Figure 12 all make it relatively easy to report a problem or solve it. Fixmystreet, CleanUp!, BuitenBeter and Verbeterdebuurt all involve a 'quick fix' that is beneficial for all stakeholders involved; the citizen as data-submitter can directly benefit from reporting trash by having a cleaner street, while the municipality is informed correctly and can act adequately. As we stated earlier in this paper, we are rather more interested in more complex issues - where the logic of reporting-fixing does not suffice. The last five applications engage with these more open-ended questions. We will reflect on the challenges that designers/design researchers of these 'different' apps face.

The first five apps are set up by companies, NGO’s and the Municipality. Different to the applications that are created by designers/design researchers, the apps that are set up by companies and NGO's almost all have a continuous and active usage. This can be explained by the fact that they have a budget for marketing campaigns to promote the apps and that a higher investment was made to improve the UX and visual design of the apps. From the user side, the app is free of cost; citizens can create an account and add reports for free. In order for municipalities to respond to these reports, however, they need to connect to the API's of these corporate tools and for this, they need to pay. Connecting the company's API to that of the municipality is what the business model of such companies is often based on. This might also give an explanation as to why these API's are not publicly available. Another factor that explains why the user activity is higher in the first five projects is that direct involvement of the municipality and clear feedback seem to be important issues for continuous usage of an app. For the see-clickfix apps and platforms, it shows that if the municipality acts on the first report added by a user there is a significant higher chance that the same user will report another time (Sjoberg et al., 2015). 
Figure 12 Eleven apps (including the first two presented in the paper) compared and placed in a taxonomy

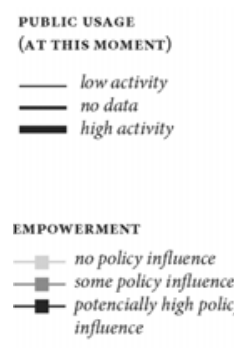

\author{
Short/continuous \\ term usage
}

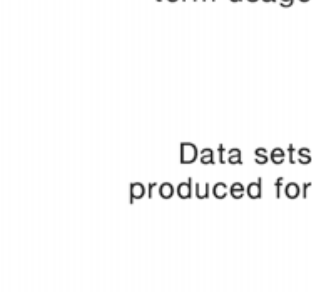

Municipality can direcly act on data

Data contains predefined categories

Data can be traced back to individual

How data is gathered

Publicly accessible API

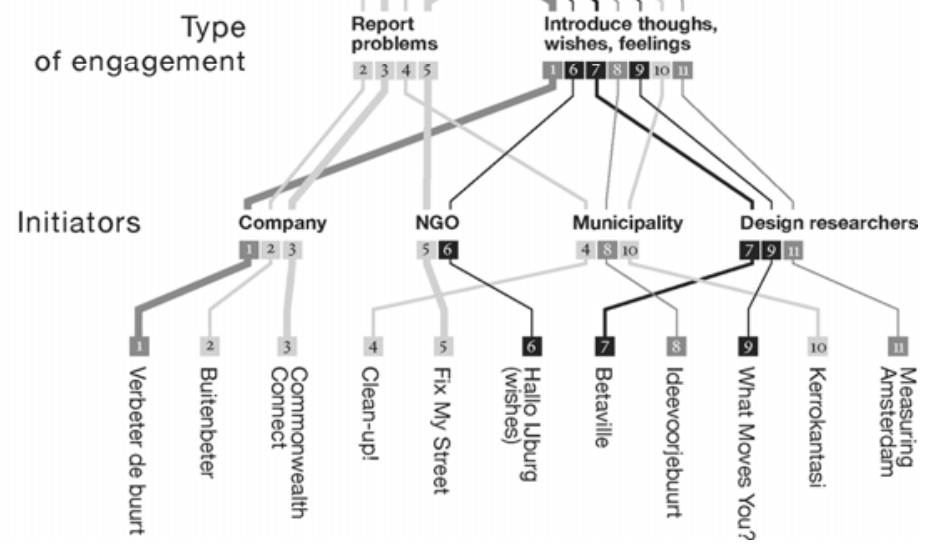

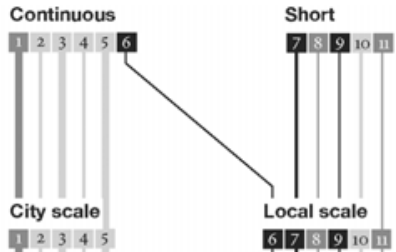
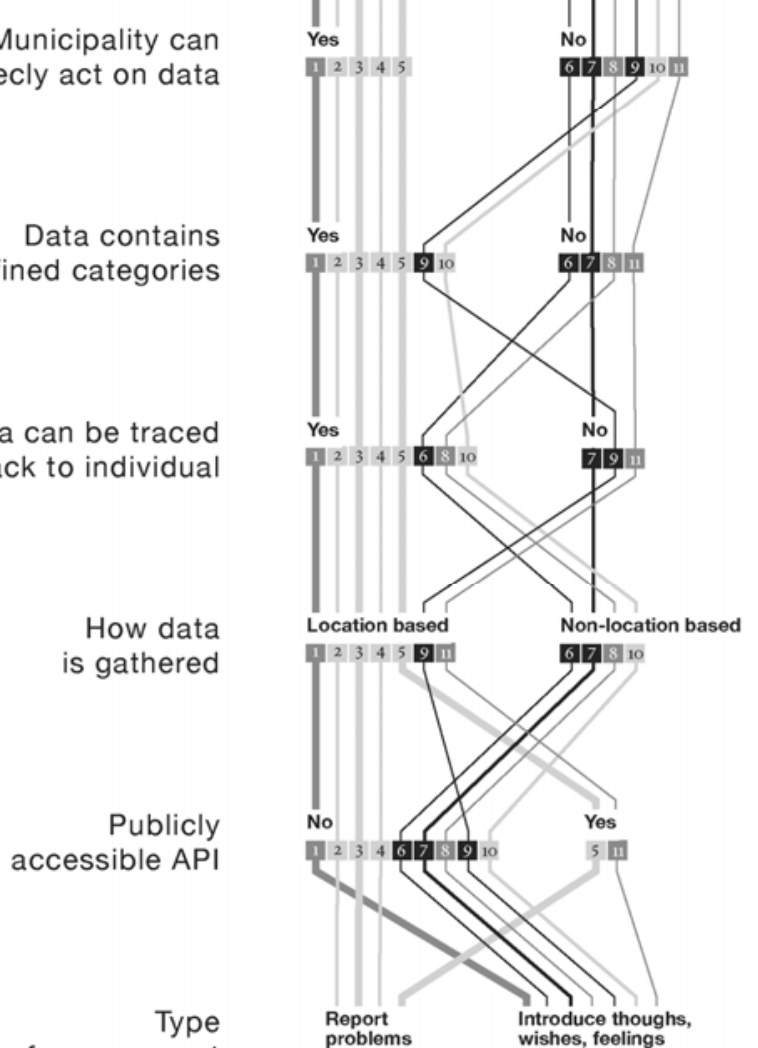
2. 3415 - 
These first five apps almost all involve submitting data on a 'city-wide scale'. With this, we mean that the data is derived from an individual who reports an issue on the city's infrastructural level, rather than data that tells us something about a local community or the interest of an individual regarding a certain neighbourhood. We see this kind of reporting as contributing to a lighter form of empowerment as it does not engage with issues that give rise to a subjective and communal perception of public space or local knowledge. In location-based apps, the datapoint carries a geotag which allows citizens to communicate something about a certain issue by being physically present on the spot and through an engagement with the local context or media-related subject. We find the engagement with a site and context important criteria when it comes to producing and submitting local knowledge. Location based apps, in which this attribute is derived from the context rather than adding data from a desktop application, are therefore more interesting for our goal. For this reason we find the web app Betaville less empowering as the data does not involve engaging with the everyday 'messiness' of public space, but rather involves drawing proposals (in the form of 3D models) for improving a public space from behind a desktop, which can easily distance someone from the complexities of everyday life. Design choices within the application are crucial in contributing to this form of engagement. Predefined categories, for instance, might limit the user in introducing thoughts, values or feelings regarding a communal or local issue.

\section{General discussion}

Empowerment involves the ability of people gaining control and awareness over the social and political matters and taking action to improve their lives in accordance with this understanding. Of relevance is being able to eventually influence policy, with which we see potentials for a more sustainable and empowering use of participatory tools. Within the scope of designing civic apps, this can be achieved in three ways: empowerment that involves the reporting of problems, the empowerment that involves the introduction of new ideas, and empowerment that involves the introduction of thoughts, feelings, and wishes regarding a local issue. Having the perspective of empowerment as an objective, we consider apps that enable citizens to express local and communal issues regarding public space to have more potentials as they can function as entry points for tailoring policy or urban design on a neighbourhood scale.

In this paper, we analysed apps that claim to empower citizens in some way or another. Many applications and community platforms, we found, focus on the exact same thing: reporting specific problems on city-scale infrastructural issues. FixMyStreet, CleanUp! and BuitenBeter are examples of such apps. We believe that the kind of data-sets that are produced with these apps are less influential when it comes to changing or adapting policy to a local context or as a potentially relevant contribution to area development plans. The last five applications of the taxonomy are different in this respect as they work with annotations such as wishes, feelings and expressions, in the form of free text input, photos (in the case of Measuring Amsterdam and What Moves You?) or drawings (in the case of Betaville). But these applications have very little active usage compared to the former three. The taxonomy shows us that there seems to be an imbalance between active usage and applications that provide more 'rich' and 'locally engendered' data. Through the analysis and proposed taxonomy, we are also able to see different explanations for this, such as the fact that the municipality cannot work with 
these non-standardised data-sets (they only work with predefined variables) or the fact that these apps are made by companies who have more to invest in the marketing. One's perception of a place and specific local knowledge or community values are potentially significant data to work with when it comes to tailoring policy and urban planning to local needs. We not only believe that this approach can help empower citizens in more relevant ways, but see the challenge for other stakeholders (such as municipalities) to engage more with these kinds of civic apps.

With Measuring Amsterdam, we strived to explore the use of a tool that enables citizens to report about observations in their neighbourhood, i.e., issues that citizens themselves find important to raise. We then investigated the interest for such tools within the municipality as a way to incorporate citizens' aspirations and priorities in area development plans. The project has taught us the importance of investigating the limitations and expectations of the stakeholders involved prior to starting the design phase. We see a potential for designers and design researchers to work with this local knowledge so that it can be used for public space design.

When it comes to discrepancies in participation, the challenge that we are faced with is that most people have busy lives or citizens do not see the benefits of such tools which often is accompanied by data illiteracy. It is very hard to find incentives for citizens to use such tools and over a longer period of time. The challenge for designers and design researchers is to avoid becoming educators by providing citizens with data-literacy. The answers, we believe, lie in the design discipline itself. Designers and design researchers should explore ways for citizens to feel empowered when using such tools. We discovered that feeling empowered does not necessarily mean that the application has to have a continuous use; it can also be achieved in short-term usage such as during an event or in a game. What is important is to create incentives for participation with design techniques, for instance by giving citizens direct feedback, as real-time mapping can be a strong incentive for participation.

\section{Conclusion}

In this paper, we aimed to provide an overview of the involvement kinds and levels of different stakeholders in a mobile/web app development project intended for citizen participation in public issues. Our approach to this subject was two-fold: First, we identified two discrepancies that we encountered while creating our own civic apps and discussed the lessons we learned through these cases. Second, we presented an overview of the most prominent apps that exist in the current market intended for engaging citizens in resolving public issues and discussed them in the light of nine criteria. We consider that both of these approaches can help in understanding the context that such mobile/web apps operate in, as well as showing what makes these apps succeed in long-term engagement with their users. Consequently, we believe that our analyses might lead to better research questions from the perspective of designers and design researchers working in projects from this domain and trigger reflection on the use and benefits of such participatory tools.

Although we focused on empowerment as an outcome of being actively engaged in a local issue, we consider that empowerment at the local level can be a vehicle for attaining empowerment at a higher level. As Dom (2012, p.4) aptly puts forward, 
"When people become confident in their ability to change local policies or overcome local obstacles, they may subsequently feel empowered to tackle challenges at a wider, possibly regional or national, level”. In civic apps, there is this strong potential.

\section{References}

Air Quality Egg Project (n.d.) http://airqualityegg.com (Accessed 20 December, 2016).

Almirall, E. and Wareham, J. (2011) 'Living labs: arbiters of mid-and ground-level innovation', Technology Analysis and Strategic Management, Vol. 23, No. 1, pp.87-102.

Brown, G. and Kyttä, M. (2014) 'Key issues and research priorities for public participation GIS (PPGIS): a synthesis based on empirical research', Applied Geography, Vol. 46, pp.122-136.

Cornwall, A. (2008) 'Unpacking'Participation: Models, meanings and practices', Community Development Journal, Vol. 43, No. 3, pp.269-283.

Cornwall, A. and Gaventa, J. (2001) 'Bridging the gap: citizenship, participation and accountability’, PLA Notes, Vol. 40, No. 2001, pp.32-35.

Cruikshank, J. (2014) Do Glaciers Listen?: Local Knowledge, Colonial Encounters and Social Imagination, UBC Press, Vancouver, Canada, p.9.

De Gebiedscyclus (2016) Gemeente Amsterdam, https://www.amsterdam.nl/gemeente/volgbeleid/gebiedsgericht/artikelen/gebiedscyclus (Accessed 20 December, 2016).

Diez, T. and Posada, A. (2013) 'The fab and the smart city: the use of machines and technology for the city production by its citizens', Proceedings of the 7th International Conference on Tangible, Embedded and Embodied Interaction, ACM, Barcelona, Spain, February, pp.447-454.

Dom, C. (2012) Empowerment Through Local Citizenship. Poverty Reduction and Pro-Poor Growth, pp.107-136.

Doyle, N. (2008) Civic Engagement in Queensland Australia: Participation in Road System Management A Case Study of Main Roads Experience, Queensland. Building Trust through Civic Engagement, p.157, http://unpan1.un.org/intradoc/groups/public/documents/un/ unpan028357 2.pdf\#page=162 (Accessed 20 December, 2016).

Fix My Street (n.d.) https://www.fixmystreet.com (Accessed 20 December, 2016).

Gurstein, M.B. (2011) 'Open data: empowering the empowered or effective data use for everyone?’, First Monday, Vol. 16, No. 2, http://firstmonday.org/article/view/3316/2764

Hilton, M., McKay, J., Crowson, N. and Mouhot, J-F. (2010) The Big Society': Civic Participation and the State in Modern Britain, 26 August, http://www.historyandpolicy.org/policypapers/papers/the-big-society-civic-participation-and-the-state-in-modern-britain (Accessed 20 December, 2016).

Holohan, A. and Garg, A. (2005) 'Collaboration online: the example of distributed computing', Journal of Computer-Mediated Communication, Vol. 10, No. 4, https://academic.oup.com/ jcmc/article/10/4/JCMC10415/4614490

Israel, B.A., Checkoway, B., Schulz, A. and Zimmerman, M. (1994) 'Health education and community empowerment: conceptualizing and measuring perceptions of individual, organizational and community control', Health Education and Behavior, Vol. 21, No. 2, pp.149-170.

King, S.F. and Brown, P. (2007) 'Fix my street or else: using the internet to voice local public service concerns', Proceedings of the 1st International Conference on Theory and Practice of Electronic Governance, ACM, December, Macao, China, pp.72-80.

Knowledge Mile (n.d.) http://www.knowledgemile.org (Accessed 20 December, 2016).

Lee, M., Almirall, E. and Wareham, J. (2016) 'Open data and civic apps: first-generation failures, second-generation improvements’, Communications of the ACM, Vol. 59, No. 1, pp.82-89. 
Lowndes, V. and Sullivan, H. (2004) 'Like a horse and carriage or a fish on a bicycle: how well do local partnerships and public participation go together?’, Local Government Studies, Vol. 30, No. 1, pp.51-73.

Measuring Amsterdam (2014) http://measuringamsterdam.nl (Accessed 20 December, 2016).

Nath, J. (2011) 'Reimagining government in the digital age', National Civic Review, Vol. 100, No. 3, pp.19-23.

Patel, R. (2015) A Guide to Open311, Partridge Publishing, Gurgaon, India.

Pimbert, M. and Wakeford, T. (2001) 'Overview: deliberative democracy and citizen empowerment', PLA Notes, Vol. 40, pp.23-28.

Raddick, M.J., Bracey, G., Gay, P.L., Lintott, C.J., Murray, P., Schawinski, K., Szalay, A.S. and Vandenberg, J. (2013) Galaxy Zoo: Exploring the Motivations of Citizen Science Volunteers, arXiv preprint arXiv: (0909)2925.

Sandoval-Almazan, R., Gil-Garcia, J.R., Luna-Reyes, L.F., Luna, D.E. and Rojas-Romero, Y. (2012) 'Open government 2.0: citizen empowerment through open data, web and mobile apps', Proceedings of the 6th International Conference on Theory and Practice of Electronic Governance, ACM, October, Albany, NY, USA, pp.30-33.

SeeClickFix (n.d.) https://seeclickfix.com (Accessed 20 December, 2016).

Sjoberg, F.M., Mellon, J. and Peixoto, T. (2015) The Effect of Government Responsiveness on Future Political Participation, 26 February, https://papers.ssrn.com/sol3/papers.cfm? abstract_id=2570898 (Accessed 20 December, 2016).

Smart Citizen Project (n.d.) https://smartcitizen.me (Accessed 20 December, 2016).

Urban Forest Map (n.d.) http://urbanforestmap.org (Accessed 20 December, 2016).

What Moves You? Project (2015) http://performativemapping.com/what-moves-you-a-collectiverealtime-mapping-of-eindhovens-dutch-design-week/ (Accessed 16 January, 2016).

Zimmerman, M.A. (2000) 'Empowerment theory', in Rappaport, J. and Seidman, E. (Eds.): Handbook of Community Psychology, Springer, US, New York, pp.43-63. 